\title{
Management of Severe Penetrating Chest Trauma: Focusing on Cardiac Injury
}

\author{
Mindaugas Rackauskas ${ }^{1 *}$, Romaldas Rubikas ${ }^{2}$ \\ ${ }^{1,2}$ Department of Heart, thoracic and vascular surgery, Hospital of Lithuanian University of Health Sciences \\ Kaunas Clinics, Eiveniu str. 2, LT-50009 Kaunas, Lithuania
}

*Corresponding Author: Mindaugas Rackauskas, Department of Heart, thoracic and vascular surgery, Hospital of Lithuanian University of Health Sciences Kaunas Clinics, Eiveniu str. 2, LT-50009 Kaunas, Lithuania, E-mail: mrackauskas@gmail.com

\section{Abstract}

Background: Penetrating cardiac injury is often a lethal form of trauma. Understanding the mechanisms, types and complications of cardiac injuries is important for appropriate diagnosis and treatment. The aim of this study was to report our outcomes of penetrating cardiac trauma and propose an algorithm for its management.

Patients And Methods We have retrospectively reviewed 217 patients' files of penetrating heart and pericardium injuries between September 1953 and July 2013. Patient age, gender, mechanism of injury, risk factors, associated injuries, complications and treatment were reviewed.

Results: We treated 193(89\%) patients with stab wounds and 24(12\%) patients with gunshot wounds. $185(85 \%)$ were male, mean age 37 years. Right ventricle was injured in 81 (37\%) and left ventricle in 56 (25\%) patients. Multichamber injury was found in 10 (4.6\%), pericardial injury was found in 68 (31\%), lungs 58 (27\%), small bowel 7 (3.2\%), diaphragm 15 (7\%), thyroid $1(0.5 \%)$ and spleen in $3(1.4 \%)$ patients. Cardiac tamponade was found in 2/3 of cases with blood amount from $30 \mathrm{ml}$ up to $1100 \mathrm{ml}$. Severe shock was present in $83(38 \%)$ patients. Overall operative survival rate was $81 \%$.

Conclusions: Prompt coordinated and multidisciplinary management of penetrating intrathoracic injuries can lead to good survival even from severe intrathoracic organ injuries.

Keywords: Cardiac Trauma, Stab Wound, Penetrating Cardiac Injuries, Tamponade.

\section{INTRODUCTION}

Penetrating cardiac injury remains a highly lethal form of trauma despite enormous progress in trauma care. The majority of patients will die before reaching the hospital and only $20 \%$ of patients with penetrating wounds reach the hospital alive [1]. However, patients who arrive at the hospital with intact vital signs and before cardiac arrest occur have a good chance of survival.

The first successful cardiac cardiorrhaphy was performed in 1896 by Rehn who closed a right ventricular stab wound. Subsequently Beck described the physiology and clinical signs of cardiac tamponade. Improvements in patient transport, volume resuscitation, anaesthesia, critical care and adult cardiac surgery have all combined to improve the outcome of penetrating cardiac injuries [2-4].
First time left ventricle wound in Lithuania was successfully stitched by V. Gusevas in 1928. In 1929, 1934 and 1939 V. Kuzma reported successful management of penetrating heart injury. The heart and pericardium injuries have been also reported by S. Stonkus (1940), J. Bredikis, J. Jocius, A. Dumcius (1968) and R.Rubikas (2000) [5-9].

However, operative repair of cardiac injuries was considered to be impossible and the first successful cardiorraphy was performed just over a century ago.

Understanding the mechanisms, types and complications of cardiac injuries is important for rapid diagnosis and surgical treatment. The aim of retrospective study was to analyze the mechanisms and approaches to the initial management of penetrating cardiac injuries since 1953 and based on our experience and 
outcomes we propose an algorithm for management of penetrating cardiac injury.

\section{Patients}

This is a retrospective observational study of patients treated for penetrating heart injuries between September 1953 and July 2013. Two hundred and seventeen patients were operated for cardiac and pericardium injuries. There were $185(85 \%)$ male and $32(6.8 \%)$ female patients, mean age 37 years, range 9-74. Surgical operations were performed on 193 (89\%) patients with stab wounds and 24 (12\%) patients with gunshot wounds. Chest injury wound site was variable and most common was the left front-lateral (juxtacardiac zone) side of the chest was injured in 202 patients, and in 15 patients was on the right side of the chest. Patients age, gender, mechanism of injury, operative notes, risk factors, associated injuries, complications and treatment were collected. Left anterolateral thoracotomy and median sternotomy were the approach of choice in most cases.

Data were entered into a computerized sheet (Microsoft Excel 2007; Microsoft Corporation, Redmond, Washington) and analyzed statistically using SPSS for Windows, version 17.0 (IBM SPSS, Chicago, Illinois). Values are reported as means and expressed as a percentage.

\subsection{Operative Technique}

Left anterolateral thoracotomy provides rapid access to the pericardium, heart and major vessels. However, left anterolateral thoracotomy is fast, could be extended across into the right chest as a 'clam-shell' incision, which allows access to other injuries and crossclamping of the descending thoracic aorta if the patient is close to exsanguination.

Median sternotomy gives access to the heart and great vessels and to other structures in the mediastinum. Both pleural cavities are also accessible via median sternotomy, although less easily than via left or right thoracotomy. Pericardium was opened with making an initial cut with a blade and then incision was extended with scissors. The pericardium was opened longitudinally and incision made anterior and parallel to the phrenic nerve, extending the pericardial incision as an 'inverted-T' enhances exposure. Clots and blood were evacuated from around the heart and the site of injury and cardiac rhythm ascertained. Internal cardiac massage was commenced for asystole or fibrillating heart using rapid and gentle compressions. Ventricular wounds were usually found $\sim 1.0$ $\mathrm{cm}$ in dimension and covered with clot. Standard surgical techniques were used for the cardiac repair after penetrating injury.

Ventricular bleeding was controlled by pressure with a finger or mounted gauze, then using $3 / 0$ Prolene with or without PTFE (Teflon) pledges on a large, round-bodied needle to go through both sides of the laceration in one pass of the needle. Autologous pericardium can be used as pledges. The two ends of the sutures were pulled upwards with one hand, greatly reducing bleeding as the edges of the wound were approximated. Injuries adjacent to large coronary branches were sutured using mattress sutures with bites on either side of the coronary vessel. The pericardium was left open and mediastinal and thoracic drains were placed. All patients with penetrating heart injuries were transferred to ICU for hemodynamic and respiratory function optimization. Detailed algorithm for the initial assessment and management of penetrating injuries presented in Figure 1. Algorithm demonstrates two scenarios: stable patient with different diagnostic investigations and unstable patient requiring urgent surgery. Unstable patients with penetrating thoracic and cardiac injuries should be rapidly transferred to the operating room. Considering our experience we recommend algorithm for investigation and treatment of chest and heart penetrating injury.

\section{Results}

In our study the most common sites of penetrating injuries there found in juxta cardiac zone, which is defined superiorly by the clavicles and sternal notch, laterally by the nipple line and inferiorly by the costal margins. Wounds outside the margins of the juxtacardiac zone do not exclude cardiac injury but also should be suspected with wounds to the upper abdomen, chest, back, and neck.

The mean time from injury to surgery was 1-1.5 hours in average for patients in city, while for patients from suburbs were up to 8 hours. Whereas in 1968, time to reach the hospital was 4.5 hours in city. Despite advances in emergency medical care, ambulance service, penetrating cardiac injuries continues to carry a high on-scene and immediate post injury mortality. 


\subsection{Type of Injuries Sustained And Procedures Performed}

Retrospective analysis showed right ventricle injury in $81(37 \%)$ and left ventricle injury in $56(25 \%)$ patients. Multichamber injury was in 10 cases $(4.6 \%)$. Eight patients had injury of up to $3 \mathrm{~cm}$. Isolated pericardial injury was found in $68(31 \%)$ patients. Four patients had injuries to the great vessels, and foreign body was found in $9(4.2 \%)$ patients. Sternum was injured in 5 $(2.3 \%)$ patients and neck in $1(0.5 \%)$ patient. Four patients were put on cardiopulmonary bypass machine and coronary artery injuries were sutured in two patients, one had tricuspid valve repair and one ventricular septal repair.

Despite cardiac injury, 58 (27\%) patients had lung injury. Thoracoabdominal injury had 25 (11.5\%) patients. The most common abdominal injuries were: small bowel 7 (3.2\%), diaphragm $15(7 \%)$, and spleen $3(1.4 \%)$. One patient had thyroid injury $(0.5 \%)$. Table 1 demonstrates localization of thoracic and abdominal organs injuries. Explorative laparotomy was performed in $21(9.7 \%)$ cases.

Table1. Anatomic locations of penetrating cardiac and other organs injuries

\begin{tabular}{|l|l|}
\hline Anatomic location & N (\%) \\
\hline Right ventricle & $81(37)$ \\
\hline Left ventricle & $56(25)$ \\
\hline Right atrium & $6(2.8)$ \\
\hline Left atrium & $1(0,5)$ \\
\hline Pericardium & $68(31)$ \\
\hline Lungs & $58(27)$ \\
\hline Diaphragm & $15(7.0)$ \\
\hline Right and left ventricles & $10(4.6)$ \\
\hline Small bowel & $7(3.2)$ \\
\hline Sternum & $5(2.3)$ \\
\hline Thoracic great vessels & $4(1.8)$ \\
\hline Spleen & $3(1.4)$ \\
\hline Thyroid & $1(0.5)$ \\
\hline
\end{tabular}

Cardiac tamponade was found in $2 / 3$ of patients with blood amount from $30 \mathrm{ml}$ up to $1100 \mathrm{ml}$. and hemothorax (500-2500 ml) in $64(29 \%)$ patients. Pneumothorax was found in $58(27 \%)$ patients. One third of patients had impaired consciousness, while alcohol intoxication has been found in half of the patients. $83(38 \%)$ patients presented critically unstable with severe shock. One tenth of the patients were transferred directly to the operating theatre bypassing the emergency department.

Rapid clinical diagnosis of unstable patient is based on the site of penetration, together with signs of shock, cardiac tamponade or exsanguinations, agitation, cool extremities.

\subsubsection{Postoperative Complications}

Pleural effusion $13.37 \%$, pericarditis $3.23 \%$, wound infection $2.76 \%$, pneumonia $3.69 \%$, myocardial infarction $1.38 \%$, sepsis and peritonitis $0.92 \%$, pleural empyema $1.84 \%$ and subhepatic abscess $0.5 \%$.

\subsubsection{Outcomes of Management}

The operative survival rate in our study was 81 $\%$.

\section{DISCUSSION}

Penetrating cardiothoracic injury include both stab and gunshot wounds. Typically less than 10 $\%$ of patients with penetrating cardiac injury arrive to hospital alive [10]. Nevertheless, rapid diagnosis and operation can salvage patients who would otherwise be lost [11-12]. Stabbing wounds generally occur more frequently than gunshot wounds [13]. It is understood that penetrating cardiac trauma is a highly lethal injury and those surviving to hospital have an overall mortality approaching $80 \%$. Reported mortality figures may vary widely and are dependent on mechanism of injury, presence of cardiac tamponade and mainly which heart chamber involved. In our study penetrating cardiac injury operative survival rate was $86 \%$. Causes of mortality were: delayed or improper transportation of patients to hospital, prolonged cardiovascular insufficiency, shock and brain oedema. Rhee et al showed a hospital survival from $15.3 \%$ to $91.5 \%$, on average $42.7 \%$ [14]. Despite advances in prehospital transport, and the availability and accuracy of ultrasonography for rapid diagnosis, penetrating cardiac injuries remain highly lethal.

Rhee et al reported that the overall survival rate following penetrating cardiac injury was $19.3 \%$, with rates of $9.7 \%$ for gunshot wounds and $32.6 \%$ for stab wounds [14].

The time elapsed between injury and definitive care is one of the most important predictors of survival for penetrating cardiac injuries. In one of the largest series, reported by Campbell et al including 1198 patients, it was estimated that $18 \%$ of deaths are potentially salvageable because of isolated cardiac wounds with tamponade. The same study also identified higher survival rates for patients who had surgery within a 30-minute window [10]. The right ventricle is most vulnerable to penetrating injuries. In our study, ventricular injury composed $37 \%$ of all injuries. Jagelavicius et al in his study showed the right ventricle injury in 
$40 \%$ of patients and tamponade was found in $76.5 \%$ of all cases [15]. Demetriades et al in his study reported, that the location of cardiac injury correlated with survival, with right ventricular injuries having the best prognosis. The theoretical advantage is that the right ventricle is relatively low pressure, yet with a muscular wall that can lead to effective containment of free haemorrhage [16]. Because of an anterior location, the cardiac chambers at greatest risk for injury are the right and left ventricles. Review study by Wall et al of 711 patients with penetrating cardiac trauma, showed 54\% sustained stab wounds and $42 \%$ had gunshot wounds.

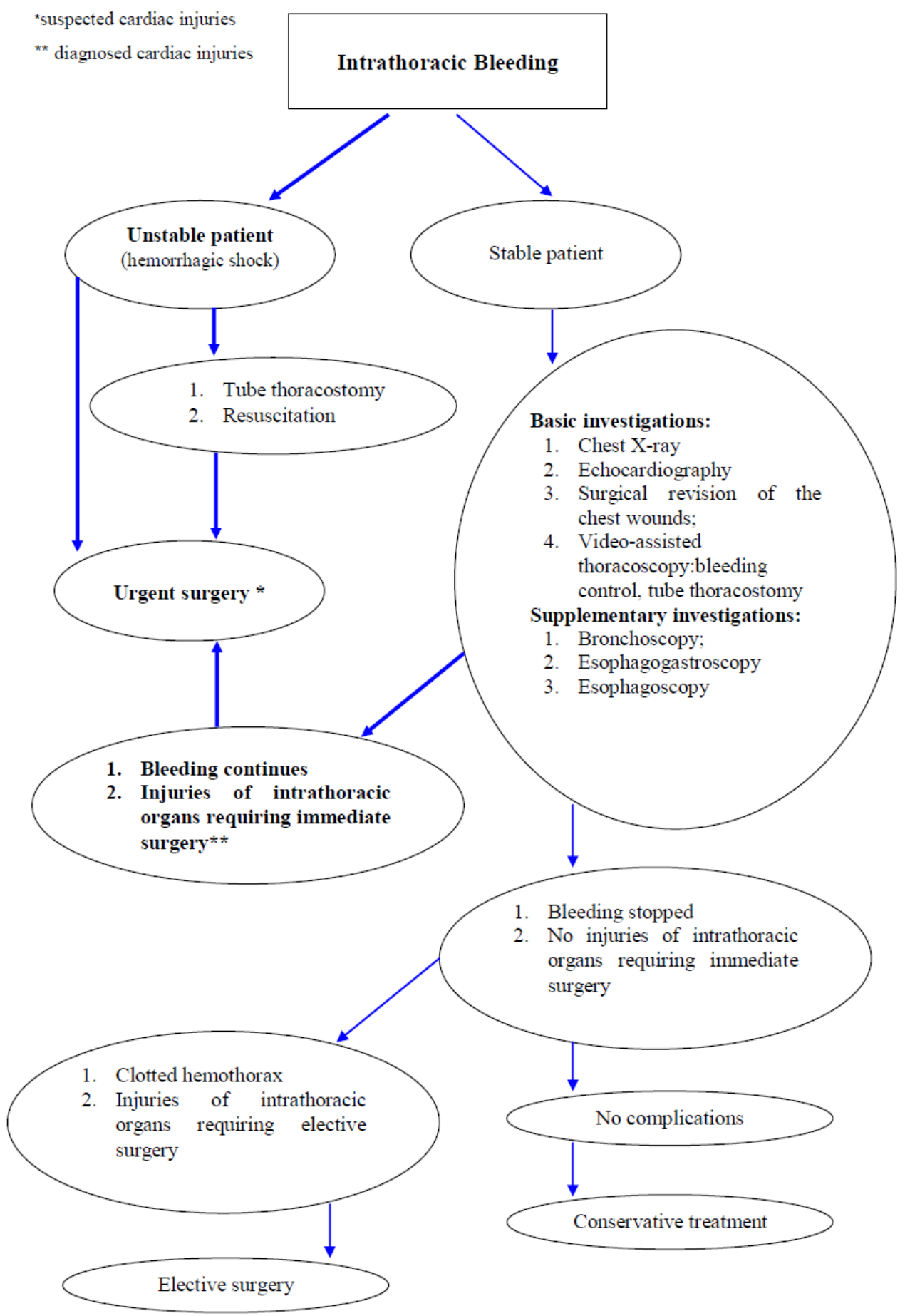

Figure1. Algorithm for the management of penetrating chest injury

The right ventricle was injured in $40 \%$ of the cases, the left ventricle in $40 \%$, the right atrium in $24 \%$, and the left atrium in $3 \%$. The overall mortality was $47 \%$. This series noted one third of cardiac injuries involved multiple cardiac structures [17]. In our study $66 \%$ of patients with penetrating ventricular wounds were presented with cardiac tamponade. Cardiac 
tamponade may prolong life by reducing the initial blood loss, but may be fatal because it interferes with venous return and diastolic filling of the heart and reduces cardiac output. The data on the survival benefit from tamponade remains controversial. While some studies demonstrated increased survival with tamponade [18], other reports have shown no benefit [19-20]. Adequate preoperative diagnostics can be conducted only in hemodynamically stable patients. In unstable patients, with signs of bleeding, heart tamponade, parasternal wound, growing hemothorax, early left anterolateral thoracotomy or medial sternotomy were indicated, without complex diagnostics. In our study clinical diagnosis of heart and pericardium injury was accurate determined in half of all patients.

Echocardiography is an excellent diagnostic tool, as it proves to be $90 \%$ sensitive and $97 \%$ specific in penetrating heart injury diagnosis [21]. In suspected heart injury, opening of the subxyphoid pericardial window can be performed as a golden standard diagnostic procedure. In our study group, alcohol intake was the main risk factor for $50 \%$ of cases with penetrating heart injuries. Time from injury to arrival at our institution was from 60 minutes to 8 hours. Velinovic et al in his study showed, that the time range to reach the hospital varies from 62 minutes to 3 days [22]. The shorter time from injury to hospital arrival is significantly important, for patient survival [23]. The algorithm for treatment of patients with penetrating cardiac trauma can be subdivided based upon the patient's vital signs (Figure 1). Management of the stable patient with systolic blood pressure $>90 \mathrm{mmHg}$ allows for more investigations including chest $\mathrm{x}$-ray, echocardiography, VATS evaluation, bronchoscopy, esophagogastroscopy. Unstable patients with systolic blood pressure $<90 \mathrm{mmHg}$ are taken directly to the operating theatre for urgent surgery.

The limitations of this study include its retrospective design, single-centre experience with relatively small numbers of patients over sixty years. Furthermore, patients in this study were treated during different periods of time. Finally, the size of our population also limits the size of our study.

With improvements in organized emergency medical transport systems, up to $45 \%$ of those who sustain significant heart injury may reach the emergency department with signs of life.
However the overall mortality of penetrating trauma has not changed much even in the major trauma centers [24]. Durham et al in his study showed that arrival to the hospital in less than 5 minutes and successful endotracheal intubation are positive factors for survival when the patient suffers a pulseless cardiac injury [25]. During the last decade, the number of heart lesions decreased in our country, as well as worldwide.

\section{Conclusions}

Penetrating cardiac injuries are associated with high mortality, which has improved only minimally in the past decades. Penetrating cardiac injuries are still one of the leading causes of death from urban violence. One third of the pericardium and heart injuries are accompanied by chest and other organ injury, and the results of surgical treatment depend on multidisciplinary teamwork. Rapid transportation to the emergency department, quick and accurate diagnosis followed by urgent surgical intervention is essential to achieve reasonable survival.

\section{REFERENCES}

[1] Sugg WL, Rea WJ, Ecker RR, et al. Penetrating wounds of the heart: an analysis of 459 cases. J Thorac Cardiovasc Surg 1968; 56: 531-545.

[2] Blalock A, Ravitch MM [1943] A consideration of the non-operative treatment of cardiac tamponade resulting from wounds of the heart. Surgery 14:157-162.

[3] Landmarks in Cardiac Surgery. Westaby and Bosher. Informla Health Care, 1997.

[4] Asensio, Juan A. [2001] Penetrating Cardiac Injuries: A Complex challenge. Surg Today 31:1041-1053

[5] Bredikis J, Jocius J, Dumcius A. Injuries of heart and pericardium in Kaunas. Medicina 1968;10:109-13(in Lithuanian)

[6] Rubikas R. Urgent thoracic surgery. Kaunas. KMU publishing house.2000.pp.189-214(in Lithuanian)

[7] Gusevas V. 2 cardiac suture motivated punctured injury.Medicina.1927;7. (in Lithuanian)

[8] Stonkus S. Operated one more heart injury event. Medicina 1940;3:200-3(in Lithuanian)

[9] Dzanelidze JJ. Heart and opcat blood vessel surgery. Medicina 1953;3:65-91(in Lithuanian)

[10] Campbell NC, Thomson SR, Muckart DJ, Meumann CM, Van M, I, Botha JB. Review of 1198 cases of penetrating cardiac trauma. Br J Surg1997; 84: 1737-40. 
[11] Velmahos GC, Degiannis E, Souter I, Saadia R. Penetrating trauma to the heart: a relatively innocent injury. Surgery1994; 115: 694-7.

[12] Velmahos GC, Degiannis E, Souter I, Allwood AC, Saadia R. Outcome of a strict policy on emergency department thoracotomies. Arch Surg 1995; 130: 774-7.]

[13] Mittal V, McAleese P, Young S, CohenM. Penetrating cardiac injuries. Am Surg 1999;65:444-8.

[14] Rhee PM, Foy H, Kaufmann C, et al. Penetrating cardiac injuries: a population basedstudy. J Trauma. 1998;45(2):366-370.

[15] Jagelavičius Ž, Jovaišas V, Žilinskas A, Kybartas A, Kiškis G, Gruslys V, Liubertienė I, Janilionis R. Trauminiai penetruojantys širdies sužalojimai: 25 metų duomenų analizè. Lietuvos chirurgija 2010; 8(2): 83-93. (in Lithuanian)

[16] Demetriades D, van der Veen BW. Penetrating injuries of the heart: experience over two years in South Africa. J Trauma. 1983;23(12):10341041.

[17] Wall MJ Jr, Mattox KL, Chen CD, Baldwin JC. Acute management of complex cardiac injuries. J Trauma. 1997;42:905.

[18] Tyburski JG, Astra L, Wilson RF, Dente C, Steffes C. Factors affecting prognosis with penetrating wounds of the heart. J Trauma. 2000; 48: 587-90.
[19] O’Connor J, Ditillo M, Scalea T. Penetrating cardiac injury. J R Army Med Corps. 2009 Sep;155(3):185-90.

[20] Asensio JA, Murray J, Demetriades D, Berne J. Penetrating cardiac injuries: a prospective study of variables predicting outcomes. J Am Coll Surg. 1998; 186:24-34

[21] Jimenez E, Martin M, Krukenkamp I, Barret J. Subxiphoid pericardiotomy versus echocardiography: A prospective evaluation of the diagnosis of occult penetrating cardiac injury. Surgery 1990; 108(4): 676-80.

[22] Milos Velinovic, Dusan Velimirovic, Mile Vranes, Petar Djukic, Alesandar Mikic, Svetozar Putnik, Dragutin Savic and Bojan Nikolic. Heart Injuries - Still a Challenge for Cardiac Surgery. The Open Cardiovascular and Thoracic Surgery Journal, 2009, 2, 3842.

[23] Rashid MA, Lund JT. Trauma to the heart and thoracic aorta: the Copenhagen experience. Interact Cardiovasc Thorac Surg 2003; 2: 53-7.

[24] Thourani VH, Feliciano DV, Cooper WA, et al. Penetrating cardiac trauma at an urban trauma center: a 22 year perspective. Am Surg. 1999; 65:811.

[25] Durham LA, Richardson R, Wall MJ, et al. Emergency center thoracotomy: impact of prehospital resuscitation. J Trauma. 1992; 32:779.

Citation: Mindaugas Rackauskas \& Romaldas Rubikas. Management of Severe Penetrating Chest Trauma: Focusing on Cardiac Injury. ARC Journal of Surgery.2018; 4(1):9-14. doi: dx.doi.org/ 10.20431/2455-572X. 0401003 .

Copyright: (C) 2018 Authors. This is an open-access article distributed under the terms of the Creative Commons Attribution License, which permits unrestricted use, distribution, and reproduction in any medium, provided the original author and source are credited. 